Política y Sociedad

ISSN-e: 1988-3129

\title{
Solo conocido por Dios. Problematización y gobierno de los cuerpos de soldados argentinos sepultos en Malvinas
}

\author{
Daniel Chao ${ }^{1}$
}

Enviado: 29-01-2019 // Aceptado: 30-09-2021

Resumen. Orientado por los estudios en gubernamentalidad, el artículo aborda el tratamiento político de los soldados argentinos sepultos en Malvinas como problematización gubernamental. El texto está dividido en dos partes. En la primera se desarrolla el enfoque WPR que interroga las políticas públicas a partir de la forma en que los problemas son representados, es decir no tomando a la política como un ámbito de resolución sino de creación de problemas como modo de hacer inteligible su espacio de acción y posibilitar las prácticas de gobierno. En la segunda parte se aborda una serie de textos políticos producidos desde el Estado argentino entre 1982 y 2015 que problematizaron el estatus de los cuerpos enterrados en Malvinas, su identificación, su relación con la soberanía y simultáneamente la posibilidad de que sus deudos puedan llevar a cabo el rito del duelo. Concluimos mostrando que el modo de presentar el problema de los caídos y sepultos no varió desde las primeras propuestas militares, pese a la estabilización de la democracia en el país.

Palabras clave: guerra; posguerra; Malvinas; Argentina; cuerpos; sepultos; problematización; enfoque WPR; gubernamentalidad

\section{[en] Know only to God. Problematization and government of the argentine soldiers bodies buried in Malvinas}

\begin{abstract}
Oriented by the studies on governmentality, this paper analyzes the emergence of the Argentine soldiers buried in the Falklands as governmental problematization. In the first part we develop the WPR approach that interrogates the political proposals as discourses, based on the ways in which the problems are represented, that is, not taking politics as a sphere of resolution but of creating problems in order to make intelligible its space of action and government. In the second part we approach a series of policies texts produced between 1982 and 2015 that focused on problematizing the status of the bodies interred in Malvinas, their identification, their relationship with sovereignty and simultaneously the possibility that their relatives can carry out the ritual of mourning. We concluded by showing that the way of presenting the problem of the dead and buried did not vary from the first military proposals, notwithstanding the stabilization of democracy.
\end{abstract}

Keywords: war; postwar; bodies; buries; Argentine; problematization; wpr approach; governmentality

Sumario. 1. Introducción. 2. Gubernamentalidad, problematización y problematizaciones gubernamentales. 3. Problematización, discurso, textos políticos. 4. El nacimiento de los sepultos en Malvinas como problema político. 4.1. Caídos y sepultos en democracia. 4.2. Monumento e identificación. Los sepultos en el siglo XXI. 5. Conclusiones. 6. Bibliografía

Como citar: Chao, D. (2021). Solo conocido por Dios. Problematización y gobierno de los cuerpos de soldados argentinos sepultos en Malvinas. Polit. Soc. (Madr.) 58(3), 63086. https://dx.doi.org/10.5209/poso.63086

\section{Introducción}

El 26 de marzo de 2018, alrededor de 200 familiares de soldados argentinos caídos en la guerra de Malvinas realizaron un viaje hasta las islas con el fin de colocar una placa con nombre y apellido a 90 tumbas sin identificación que forman parte del cementerio de guerra (1lamado Cementerio de Darwin). Más de 35 años después (la guerra finalizó en junio de 1982), y tras un arduo trabajo de la Cruz Roja Internacional y el Equipo Argentino de Antropología Forense ${ }^{2}$, casi un centenar de soldados muertos que figuraban como NN fueron identifi-

Instituto de Investigaciones Geohistóricas (CONICET-UNNE), (Argentina).

E-mail: 1.daniel.chao@gmail.com

2 El Equipo Argentino de Antropología Forense (EAAF) es un organismo científico forense no gubernamental creado en 1984 que inició su labor identificando restos vinculados a los desaparecidos en la última dictadura militar argentina (1976-1983). Con los años, por su labor y trayectoria se expandió a otros casos de violaciones de derechos humanos a nivel internacional. 
cados y sus familiares y seres queridos cuentan con la certeza del lugar donde yacen sus restos. Esta escueta presentación genera una pregunta: ¿cuáles fueron las razones que justificaron esta demora?

Las siguientes líneas intentarán esbozar algunas respuestas centradas en el papel que le cupo al Estado nacional, no en el objetivo de restituir la identidad a los muertos en combate sino, al contrario, en crear las posibilidades para que esa restitución se materialice tres décadas después de la rendición argentina. Para ello nos centraremos en la emergencia y devenir de los cuerpos sepultos en Malvinas como problema político, a través de un corpus de textos de diferentes instituciones emitidos y firmados por sujetos que se presentan como portavoces del Estado nacional.

Siguiendo algunas bases de la analítica de la gubernamentalidad ${ }^{3}$, analizamos estos textos desde los modos en que plantean conducciones de conductas, es decir desde discursos que muestran caminos de modificación de la vida de los sujetos a los que están dirigidos indicando las mejores soluciones posibles para asegurar su bien y evitar su mal (Gordon, 2015). Para ello, apelamos a la noción de problematización gubernamental (Bacchi y Goodwin, 2016) como un conjunto de prácticas que permiten que algo se convierta en objeto de pensamiento e ingrese al mundo de lo verdadero, y en ese hiato haga posible su visibilidad como objeto de gobierno. A nivel analítico, y en el plano que nos interesa, esas prácticas se materializan en las propuestas explícitas presentes en los textos políticos, a las que entendemos como respuestas a preguntas que no necesariamente están presentes pero pueden rearmarse a partir del problema representado en cuestión.

Sobre esta base, analizaremos un corpus heterogéneo de discursos que tomaron a los cuerpos de soldados argentinos enterrados en Malvinas como problema de Estado, cruzándolos con el conjunto de sentidos ligados a la guerra: soberanía, patria, nacionalidad, argentinidad. Intentaremos dar cuenta de cómo la problematización que la dictadura militar argentina instituyó a fines de 1982 marcó a fuego la trayectoria histórica posterior en democracia, la cual aún tiene injerencias que no pueden ser removidas y que marcan uno de los aspectos más potentes del discurso y su relación con el poder: la productividad concreta en el gobierno de la vida, la muerte y las posibilidades de duelo. Nuestro escrito se estructurará en dos partes. En la primera, destacaremos algunos aspectos del marco teórico y la metodología de trabajo, ligada al enfoque WPR ${ }^{4}$ (Bacchi, 2009) sobre políticas públicas que presta especial atención al modo en que los problemas son representados en las propuestas de intervención sobre lo social. En la segunda parte, desarrollaremos nuestro análisis a partir de la lectura de las problematizaciones presentes en una diversidad de textos políticos que abarcan los años 1982 hasta principios de 2015. Estos textos incluyen documentos militares, discursos y decretos presidenciales, informes y actas de acuerdo bilaterales, debates parlamentarios y proyectos de ley presentados en el Congreso Nacional, y se centran en algunos momentos claves: el primer año de posguerra; la década de los 90 en la que se destaca la posibilidad de los familiares de realizar viajes hacia las Malvinas; la inauguración del monumento a los caídos y posterior problematización de la necesidad de identificar los restos $\mathrm{NN}$, sucedida a mediados de la primera década del nuevo milenio.

\section{Gubernamentalidad, problematización y problematizaciones gubernamentales}

La noción de problematización vinculada a las lecturas que Michel Foucault $(1999 ; 2012)$ propuso para comprender el pensamiento en la heterogeneidad de relaciones de poder, fue recuperada por diversos autores ligados a la analítica de la gubernamentalidad, como otros lectores de la obra foucaultiana (Castel, 1997; Deacon, 2000), en tanto concepto metodológico clave. No obstante, ninguno de ellos se preocupó tanto por dotarla de un armazón de análisis como la politóloga canadiense-australiana Carol Lee Bacchi (2009, Bacchi y Goodwin, 2016). A fines de la década de los 90 , Bacchi presentó un modelo de abordaje al que sintetizó mediante una pregunta de difícil traducción al español: what's the problem represented to be? (¿cuál es el problema repre-

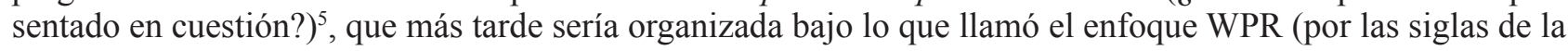
pregunta en su idioma original).

En sus palabras, su perspectiva apunta principalmente al análisis de las políticas públicas bajo la premisa básica de que éstas funcionan como palancas para entender el modo en que somos gobernados, y este entendimiento parte de no suponer la existencia de problemas por fuera de los modos en que son presentados. En definitiva, las políticas públicas contienen en su formulación un diagnóstico y definición del problema que dicen buscar resolver, por lo cual antes que reaccionar ante problemáticas realmente existentes las propuestas crean los problemas dotándolos de inteligibilidad. En ese sentido, el gobierno (es decir, en términos foucaul-

La noción de analítica de la gubernamentalidad o estudios en gubernamentalidad está asociada a los análisis de un grupo diverso de intelectuales que desde mediados de la década de los 80' conectaron la noción foucaultiana de gobierno con sus propios trabajos. Entre ellos puede mencionarse a Colin Gordon, Mitchell Dean, Peter Miller, Nikolas Rose, Pat O’Malley, Mariana Valverde, entre otros. Asimismo, el enfoque es deudor del conjunto de trabajos publicados bajo el nombre The Foucault effect. Studies in governmentaliy (1991) editado por Graham Burchell, Colin Gordon y Peter Miller.

Siglas de la pregunta "what's the problem represented to be?".

Dadas las dificultades de proponer una traducción satisfactoria optamos por modificar el to be por el sintagma en cuestión, apelando a la raíz etimológica del término. Cabe destacar que aún no contamos con traducciones de la autora al español o portugués, por lo tanto toda cita directa fue traducida por el autor de este artículo. 
tianos, el arte de conducir conductas) se lleva a cabo a través de problematizaciones entendidas como redes de representaciones de problemas que poseen diversos efectos. En otras palabras, la problematización permite el gobierno puesto que este

se facilita a través de estilos de problematización que afectan nuestras vidas y nos impulsan a actuar de maneras particulares (...) los estilos particulares de problematización posibilitan el gobierno al producir individuos como 'sujetos gobernables' (Bacchi, 2015: 6-7).

Por lo cual, el foco debe situarse en las problematizaciones gubernamentales (Bacchi y Goodwin, 2016: 39).

\section{Problematización, discurso, textos políticos}

En base a estas primeras premisas, ¿cómo hacer operativo el análisis de esta problematización gubernamental? Si partimos de que los problemas son producidos como problemas particulares junto a las propuestas políticas, la mirada del analista debe posicionarse en las soluciones postuladas en un determinado programa de gobierno y preguntarse "si se sugiere esta forma de cambio e intervención, ¿cuál es el problema representado en cuestión?" (Bacchi, 2009: XII). Para rastrear esas prácticas de gobierno se parte de la concepción de textos prácticos de Foucault que se refiere a

textos que pretenden dar reglas, opiniones, consejos para comportarse como se debe (...) y que en sí mismos son objeto de 'práctica' en la medida en que están hechos para ser leídos, aprendidos, meditados, utilizados, puestos a prueba y en que buscan constituir finalmente el armazón de la conducta diaria (Foucault, 2012: 19).

Al vincular estos textos -y sus regularidades-al estudio del Estado y las políticas públicas, el enfoque WPR los definirá como textos políticos (policy texts ${ }^{6}$ ), cuyo objetivo es afectar la vida de los sujetos, presentarles guías de conducta planteadas como las mejores posibles. Estos textos pueden incluir

documentos tales como archivos y registros organizacionales, legislaciones, dictámenes judiciales, proyectos de ley, discursos, transcripciones de entrevistas (...), organigramas, presupuestos, contratos de programas, informes de investigación e incluso datos estadísticos. (...) El enfoque utiliza los textos como 'palancas' para abrir reflexiones sobre las formas de gobierno y los efectos asociados, instituidos por un modo particular de constituir un problema (Bacchi y Goodwin, 2016: 18).

Asimismo, estos textos políticos operan como programas que permiten trabajar series de textos prácticos, aunque estos no hayan sido realmente puestos en funcionamiento. Dirá Foucault que estos programas

de comportamiento, estos regímenes de jurisdicción/veridicción no son unos proyectos de realidad que fracasan. Son unos fragmentos de realidad que inducen unos efectos de lo real tan específicos como los de la división de lo verdadero y de lo falso en la manera en cómo los hombres se 'dirigen', se 'gobiernan', se 'conducen' a sí mismos y a los demás (Foucault, 1982: 71).

Podemos agregar, como enfatiza Mitchell Dean, que al centrarnos en este tipo de documentos no estamos haciendo una descripción de rutinas empíricas del gobierno estatal, sino que lo gubernamentalizamos (retomamos al Estado como resultado o efecto), lo ponemos a la luz de su multiplicidad de prácticas que "se forman en relación con las formas específicas de conocimiento y experiencia de una variedad de autoridades" (2010:39) y que entrelazan series de conjuntos de objetivos, diagnósticos, esquemas de evaluación, etc. Hay en la diversidad de textos políticos un parecido de familia, unas problematizaciones comunes que son algo más que epifenómenos del mando, pero que requieren una mirada del lenguaje como un elemento para hacer gobernable la realidad. Tras estas aclaraciones teórico-metodológicas, estamos en condiciones de abordar nuestro corpus.

A modo de aclaración metodológica, y vinculado con nuestro objeto de estudio, el enfoque WPR fue utilizado en tres dimensiones. En principio, la pregunta central por el problema en cuestión nos habilitó a identificar los textos políticos implicados en la representación del problema, ante la diversidad amplia de documentos estatales que abordan la cuestión Malvinas. En segundo lugar, y vinculado a esto, nos sirvió de apoyo para constituir el corpus analítico, al permitirnos ensamblar textos prácticos con problemas similares (lo que Bacchi denomina familias de problema). Por último, al restituir el problema en cuestión, no adentramos a la identificación de las características de los sujetos descritos, los conceptos con los que se los definen y los caminos que se les sugiere para solucionar el problema representado (Bacchi y Goodwin, 2016).

\footnotetext{
El término policy refiere a la noción de política pública usada en lengua inglesa, a diferencia de la polity (formas de gobernar o instituciones estatales) y la politics (que alude al reino de la política profesional). Para simplificar su traducción, optamos por denominarla política pero tomando en cuenta estos matices.
} 


\section{El nacimiento de los sepultos en Malvinas como problema político}

La guerra de Malvinas fue el enfrentamiento bélico llevado a cabo por las Fuerzas Armadas de Gran Bretaña y la Argentina, donde se puso en juego la soberanía del archipiélago formado por las Islas Soledad, Gran Malvinas, Georgias, Sándwich del Sur e islas aledañas ubicadas a poco más de $300 \mathrm{~km}$ de la Patagonia austral. Fue la única guerra convencional y regular contra otro Estado en la que Argentina fue protagonista durante el siglo XX y tuvo una duración de 74 días (desde el 2 de abril hasta el 14 de junio 1982), aunque de ese total poco más de 50 días se atravesó bajo fuego cruzado. Además de la derrota militar del país sudamericano, la guerra se llevó 649 vidas argentinas, 255 británicas y millares de heridos y mutilados en ambos bandos. El alto al fuego devino en un cimbronazo político y cultural que llevó al colapso a la sangrienta dictadura militar que comandaba el país desde 1976 (su paso estuvo caracterizado por el horror: 30 mil desaparecidos y miles de muertos y exiliados), y desembocó en la renuncia del presidente de facto General Leopoldo Galtieri y el inicio de una reanudación democrática que se materializaría en los comicios de 1983 donde resultó ganador el candidato por la Unión Cívica Radical (en adelante UCR), Rául Alfonsín (1983-1989).

No obstante, entre la rendición y la entrega del gobierno al poder civil (casi un año y medio después), el proceso de posguerra tuvo ciertas particularidades ligadas al intento de la Junta Militar (JM) abandonar el manejo del Estado sin perder legitimidad política y social. La guerra y la aceptación popular que tuvo fueron uno de los apoyos principales para ese fin, y el uso los caídos en combate como símbolos de nacionalidad y soberanía también. Las Fuerzas Armadas presentaron a los muertos en Malvinas como un sostén de derechos sobre las islas y plantearon llevar a cabo un intento de convencer a los familiares de no intentar recuperar a los cuerpos hasta que en el archipiélago no flameara la bandera argentina.

En noviembre de 1982 el gobierno británico presentó una nota al General Reynaldo Bignone (presidente de facto que reemplazó a Galtieri) donde se explicaba que en los recientes campos de batalla aún quedaban cuerpos argentinos insepultos y preguntaban cómo procedería el Estado argentino ante la situación. Federico Lorenz detalla que

el gobierno militar contestó recién en enero de 1983: autorizaba a las autoridades británicas a realizar el entierro de sus soldados caídos pero 'reservándose el derecho a decidir, cuando [fuera] adecuado, acerca del traslado de los restos de los soldados argentinos desde esa parte de su territorio al continente' (...). En respuesta, el gobierno británico organizó el traslado de los restos de los argentinos a Puerto Darwin. (Lorenz, 2017: 121)

El lugar se conoce como el cementerio de Darwin y allí se sepultaron 237 soldados argentinos, de los cuales, y hasta 2017, 123 no estaban identificados (Panizo, 2011).

El pedido británico trascendió a la prensa argentina por lo cual el 16 de diciembre de 1982 la Junta decidió “implementar por vía de cada una de las Fuerzas una operación de acción psicológica de persona (sic) a familia o deudos, partiendo de la premisa de conseguir asentimiento de los mismos para que los restos permanezcan en la Isla" (Ministerio de Defensa, 2014: 133). El Estado Mayor General del Ejército, a través de la Jefatura de Inteligencia, circuló un documento de sistematización de acciones en el que se propuso llevar a cabo una campaña para evitar "que la subversión capitalice a su favor el dolor y/o el resentimiento de los familiares de nuestros soldados muertos y desaparecidos", a lo que agregaba otra "de divulgación de reconocimientos y 'reparaciones' que el Estado contempla para los heridos, muertos y desaparecidos en esta gesta heroica" (Ministerio de Defensa, 2014: 134).

En sintonía con esta acción, a principios de 1983 miembros la Fuerza Aérea redactaron un Estudio de Estado Mayor, denominado "Traslado de restos del personal caído e inhumado en Malvinas", el cual retomaba el problema planteado por la JM. El texto partía de la "natural y lógica expectativa en los familiares de los soldados para obtener los restos de sus seres queridos" para el cual se proyectaban dos soluciones: a) "Efectuar el traslado de restos, realizando a su arribo una solemne ceremonia conjunta, y posterior entrega de los mismos a sus familiares"; y b) "Construir un monumento o cementerio (tipo Arlingtown" [sic]) para que en forma simbólica se rindan los honores y respetos a los caídos dejando el traslado de los restos para cuando se produzca la recuperación definitiva de las islas". Optar por la primera solución, implicaría no sólo negociar con el enemigo, también quitaría "la posibilidad del incentivo que significa la presencia latente de argentinos enterrados en la tierra patria de las Malvinas", por lo cual se optó por la segunda ya que, en los términos militares, lograba "atemperar las expectativas al brindar a corto plazo un lugar físico para que los familiares puedan honrar y visitar simbólicamente sus muertos pensando orgullosos en la presencia de sus seres queridos en tierra irredenta". De esta forma, el cuerpo de los muertos se volvió dato político y problema de Estado en el pensamiento militar, puesto que "la presencia silente de nuestros Muertos en Malvinas, constituye un hecho irrefutable de soberanía” (Fuerza Aérea Argentina, 1983).

A este aspecto simbólico debe agregarse otra circunstancia fundamental que refuerza nuestro argumento: el desconocimiento del Estado argentino sobre el total de muertos y enterrados, y sus identidades. A fines de

El documento hace referencia al cementerio militar de Arlington, situado en la ciudad de Washington, Estados Unidos, que ostenta la famosa tumba al soldado desconocido. 
1983, el Estado Mayor Conjunto pidió un informe al Ministerio de Relaciones Exteriores sobre el proceso de inhumación que detalló las falencias sobre todo de los soldados argentinos al momento de reconocer a los caídos. El informe resaltó que el personal argentino desconocía el procedimiento reglamentario de identificación y no tomó en cuenta la posibilidad del traslado a un nuevo cementerio. Asimismo, se señaló una ignorancia total de la Convención de Ginebra, acción de la Cruz Roja y fallas en las placas de identificación ("placas sin grabar, identificaciones de cartón recubiertas con cinta plástica, uso de hilo para colgar las placas") lo cual dejó a una gran cantidad de soldados sin posibilidades de reconocimiento posterior. De la misma manera, cada Fuerza llevó a cabo su propio registro necrológico, el cual en algunos puntos no coincidió con los dos enviados por los británicos (uno en noviembre de 1982 y otro en abril de 1983 con el traslado definitivo), así también se señaló la inexistencia de reglamentación conjunta y falta de documentación fidedigna posterior. El texto indicó además el problema de los familiares o $\operatorname{deudos}^{8}$ a partir de la comunicación del fallecimiento y la falta de datos, pues

hubo casos en que dicha comunicación no fue efectuada a tiempo por personal jerarquizado (lo que) produjo una reacción negativa hacia las FFAA (...) generando situaciones de malestar que rápidamente son captadas por la prensa y explotadas por la acción psicológica del ENO -enemigo, aclaración nuestra- (Ministerio de Relaciones Exteriores, 1983).

Por lo cual se exhortaba a las FF AA a establecer puentes de comunicación directa con los familiares a fines de contener los problemas políticos que puedan generar y de los que otros puedan aprovecharse. Presencia latente y soberana, y desconocimiento de las identidades de una parte importante de los cuerpos enterrados, se erigieron como dos extremos de un mismo problema.

\subsection{Caídos y sepultos en democracia}

En diciembre de 1983 asumió la presidencia por voto popular el referente de la Unión Cívica Radical ${ }^{9}$, Raúl Alfonsín. Con su asunción inició un proceso de reposicionamiento de la guerra que tuvo diversas derivas (Guber, 2001; Lorenz, 2012; Palermo, 2014). No obstante, el problema de la re inhumación ${ }^{10}$ de los caídos en Malvinas y enterrados en Darwin estuvo prácticamente ausente de la práctica política durante toda la década de los 80. Sin embargo, la presencia de los cuerpos enterrados en Malvinas abonó los argumentos de heroización iniciales instituidos por la Junta Militar en algunos debates parlamentarios. Tal es el caso del diputado Lorenzo Pepe (Partido Justicialista, en adelante PJ), en el primer homenaje de la Cámara de Diputados en 1984 cuando afirmó que "ahí están los huesos de nuestros soldados en Malvinas. Muchos plantean el retorno de las osamentas al continente. Yo creo que el juramento de este pueblo debe ser el de ir nosotros hacia las Malvinas" (Honorable Cámara de Diputados, 1984).

El tema reingresó como problema político recién en 1989 y bajo el mandato presidencial de Carlos Menem (1989-1999, PJ), cuando los gobiernos del Reino Unido y Argentina reiniciaron el diálogo roto desde la guerra a través de una estrategia bilateral bajo lo que se denominó el paraguas de soberanía, esto es que los intercambios comerciales se reanudarían entre ambos Estados sin tocar el tema de los derechos sobre Malvinas. En 1990 se levantó la zona de exclusión impuesta por los ingleses, y, además, entre una serie de acuerdos pesqueros y militares, bajo el auspicio y gestión de la Cruz Roja Internacional, se acordó el primer viaje de familiares al cementerio de Darwin en el que 350 personas viajaron hasta el lugar el 18 marzo de 1991 (Bologna, 1992).

Unos días antes, el 6 de marzo, el Ejecutivo emitió un decreto donde manifestó que se asumirían los gastos del viaje pues el gobierno estaba "comprometido política y emocionalmente en la realización de este viaje de carácter humanitario que permitirá a los argentinos reencontrarse con quienes ofrendaron sus vidas por la patria" (Boletín Oficial de la República Argentina, 1991) como un acto de estricta justicia. El término humanitario es una categoría utilizada comúnmente por organismos como la CICR para excluir razones políticas o ideológicas de sus acciones. En ese sentido, y bajo aquel paraguas propio del acuerdo, el contacto entre las tumbas y los deudos se presentaba como un encuentro necesario (natural como lo definió la Junta Militar), del cual los funcionarios del Estado estaban consustanciados, y que nada tenía que ver con las discusiones sobre la soberanía y el resultado de la guerra.

Como recurso de método, a partir de esta página se utiliza la cursiva para resaltar términos parafraseados que son usados en los textos analizados. Durante buena parte del período analizado se entrecruzan posiciones de los dos principales partidos políticos argentinos, nos referimos a la Unión Cívica Radical y el Partido Justicialista (denominado de modo coloquial como 'peronismo'). Estos partidos fueron mutando con el tiempo, formando alianzas electorales que los llevó en distintos momentos a la presidencia del país, hasta 2015 donde irrumpió un nuevo partido: el PRO (Propuesta Republicana), que en alianza con la UCR llevó a la presidencia al primer candidato de un tercer partido, Mauricio Macri. Más allá de este brevísimo e incompleto racconto político-institucional, la principal apuesta de este enfoque es mostrar cómo contrincantes ideológico-programáticos pueden decir lo mismo ante temas con niveles de problematización de larga duración como el que aquí se analiza.

10 Usaremos este término cada vez que nos refiramos al traslado de los cuerpos desde el Cementerio de Darwin al continente. Cabe señalar que, como han mostrado diversos autores (Guber, 2001; Panizo, 2011; Lorenz, 2012), el término repatriar (comúnmente utilizado al referirse a los cuerpos enterrados en países que no coinciden con la procedencia del difunto y por tanto se los devuelve a su patria) es incómodo para algunas organizaciones de familiares pues entienden, al igual que lo postulado por la Junta Militar, que los sepultos en Malvinas descansan en su patria. 
Paralelamente, y como una reacción de agenda, surgieron algunos proyectos parlamentarios sobre el traslado de familiares. En tanto actualización del puente entre sangre y soberanía, los proyectos homenajearon a los "que reposan en nuestros irredentes (sic) territorios" y a quienes viajaban con el amor "de toda la sociedad de la patria", (Honorable Cámara de Diputados, 1991b) y manifestaron su solidaridad hacia quienes, por razones humanitarias, se trasladarían hacia el "suelo argentino austral" que señalaba "nuestra fuerza soberana" (Honorable Cámara de Diputados, 1991a). Empero, el viaje de los familiares estuvo cargado de numerosos conflictos, a tal punto que el avión que los trasladó tuvo que borrar toda marca de argentinidad y los visitantes recibieron, según la Comisión de Familiares ${ }^{11}$, un tratamiento hostil por parte de los isleños. Las razones humanitarias y el paraguas no pudieron evitar que reaparezcan los efectos propios de la guerra, manifiestos en la actitud de los malvinenses como en la tensión que generó en los intereses del gobierno argentino por su afán de mantener las relaciones diplomáticas con sus pares británicos. Por este motivo los viajes de familiares tuvieron que esperar unos años luego de la turbulencia experimentada en 1991.

No obstante, y ante los numerosos acercamientos económicos y simbólicos entre ambos países, el problema del viaje a las tumbas se sostenía con argumentos similares. En 1996, los diputados Emilio Morello y Aldo Rico (Movimiento por la Dignidad y la Independencia, MODIN) pidieron al Ejecutivo resolver los impedimentos de los viajes, nuevamente arguyendo razones humanitarias y del derecho internacional. El derecho como tecnología de gobierno encuentra en la Convención de Ginebra una apoyatura constante para despolitizar a los cuerpos sepultos, y atribuirles a las familias la soberanía sobre sus muertos pues "ni el Reino Unido, ni la administración colonial de las islas pueden limitar o cercenar tal derecho bajo la invocación de motivo de seguridad alguno" (Honorable Cámara de Diputados, 1996). Podemos decir, entonces, que son dos las soberanías en juego: la de las familias sobre sus muertos y la de la nación sobre las islas, mediante las cuales se categorizan a los cuerpos enterrados. Ambas ficticias (los cuerpos sepultos descansan en un cementerio inaccesible e intocable para los deudos; las islas todavía son administradas políticamente por el Reino Unido) pero fuertemente reales y verdaderas en el pensamiento, y productivas en prácticas y problematizaciones.

El año 1997 -decimoquinto aniversario de la incursión militar argentina fue-, en el terreno de los cuerpos en Malvinas, un momento de alta productividad en torno a la unidad sangre-soberanía nacional. Por un lado, en ese período se declaró héroes nacionales a los caídos en Malvinas (bajo ley $\mathrm{N}^{\circ} 24.950$ ), con el argumento de que los

soldados que quedaron en Malvinas, no solo son muestra y testimonio del convencimiento del pueblo argentino de que la soberanía argentina sobre las islas australes es indelegable y que no está dispuesto a ceder ni un solo centímetro de lo que le corresponde. Sino que han quedado haciendo guardia, velando sus armas, aguardando el regreso triunfal y definitivo de los dueños de la tierra (Honorable Cámara de Diputados, 1997a).

Los cuerpos de guardia en tierra argentina, que esperan redención, es decir el regreso de Malvinas al territorio nacional, remiten sin ambigüedades a la voz militar dictatorial.

Ese mismo año se acordó con los británicos y de manera estable la posibilidad de que los familiares puedan viajar al archipiélago, mediante una coordinación entre el Ministerio de Relaciones Exteriores y la Comisión de Familiares de Caídos en Malvinas (organización que reivindica la guerra y resalta el papel jugado por los militares en el conflicto). Los dos primeros viajes se realizaron en enero y febrero de 1997 en contingentes que no superaron las 20 personas. Con los años, esta práctica se volvería asidua llegando a organizarse 24 viajes entre ese año y 2009 (Panizo, 2016: 105). Bajo esta posibilidad, y en consonancia con el aniversario venidero, el senador Eduardo Menem (PJ) propuso en febrero "constituir una delegación de senadores (...) para que efectúe un homenaje en el cementerio donde reposan los restos de nuestros conciudadanos" (Honorable Cámara de Senadores, 1997). Esos héroes nacionales que reposan en territorio argentinos merecen que los senadores, sobre la ficción de representaciones provinciales y del pueblo, llevasen la ofrenda patria bajo "razones estrictamente humanitarias y en motivaciones derivadas de un legítimo sentimiento nacional". La propuesta tuvo su réplica en la Cámara Baja a partir de dos proyectos, el de Carmen Dragicevic (PJ), por un lado, y el de Aldo Rico y Emilio Morello (MODIN), por el otro. Ambos propusieron organizar un contingente de representantes del pueblo para visitar el cementerio donde los compatriotas aguardan la recuperación. En la imaginación legislativa no hay contradicción entre la despolitización humanitaria, la afirmación de la ligazón cuerpo-soberanía y el viaje de un conjunto de sujetos -funcionarios del Estado- a visitar tumbas sin ser familiares. Sin embargo, estos viajes no se realizaron.

En estas propuestas, las dos soberanías están conectadas como un solo problema donde la patria saluda a los héroes enterrados. Paralelamente, surgieron repudios desprendidos de rumores sobre un supuesto intento de la gobernación isleña de re inhumar los cuerpos y un pacto con que el canciller Guido Di Tella logró desactivar las trabas que impedían los viajes. El diputado Mariano Viña (Movimiento Popular Fueguino) rechazó

\footnotetext{
La Comisión de Familiares de Caídos en Malvinas es un organismo creado al calor de la posguerra que nuclea familiares de soldados y oficiales caídos en combate y tuvo por mucho tiempo una postura contraria a la recuperación de los restos y su traslado a continente, y cercana a las propuestas y argumentos militares (Guerrero, 2021). Asimismo, algunos de sus miembros tuvieron y tienen cercanías con el campo militar, por ejemplo, su ex presidente, Héctor Cisneros, quien en 2010 fue acusado de pertenecer, como miembro civil, al Batallón de Inteligencia $\mathrm{N}^{\circ} 601$ durante la dictadura militar.
} 
"cualquier intento de repatriación" pues "no hay mejor tierra que pueda ofrecerles un mejor descanso, que aquella por la que dieron sus vidas. No hay tampoco para nosotros, sus deudos, un lugar mejor para llorarlos y enaltecerlos" (Honorable Cámara de Diputados, 1997b). Mientras que la diputada Fani Ceballos de Marin (Partido Renovador de Salta) se opuso "a este nuevo avasallamiento, que impide ahora el descanso en paz de quienes regaron con su sangre las heladas regiones y (sostuvo) que las visitas, legítimo derecho de los familiares, obedecen a un sentimiento estrictamente humanitario". Para la autora, había que rechazar la expatriación ya que los celosos guardianes de la soberanía "están enterrados en suelo argentino" (Honorable Cámara de Diputados, 1997c). A riesgo de ser repetitivos creemos que, montadas en la soberanía política argentina sobre Malvinas (aún bajo paraguas) y las razones humanitarias de los familiares como verdades no contradictorias, las prácticas descritas intentaron despejar de escollos cualquier obstáculo que impida la unión de esos extremos dada en el encuentro de los deudos con sus muertos.

En julio de 1999, luego de las visitas de Menem al Reino Unido y del príncipe Carlos a la Argentina, los gobiernos de ambos países firmaron una declaración conjunta de normalización de relaciones. En dicho documento, y a modo de fomento a la confianza, los países acordaron que "los ciudadanos argentinos podrán visitar las Islas Malvinas, con sus propios pasaportes" tanto si viajan por aire como por mar, y a la par los británicos permitirían construir "en el cementerio argentino en las Islas Malvinas un monumento a la memoria de los miembros de las Fuerzas Armadas argentinas muertos en acción en 1982 (Ministerio de Relaciones Exteriores, 1999). Con la firma de este documento, el mandato de Carlos Menem cumplió parcialmente el sueño que los miembros de la Junta Militar tuvieron respecto de los soldados enterrados en Malvinas (dejarlos en un stand by simbólico), aunque sin hablar sobre la soberanía territorial.

\subsection{Monumento e identificación. Los sepultos en el siglo XXI}

Tras el acuerdo con el gobierno británico, la planificación de la construcción del monumento a los caídos en el cementerio de Darwin fue delegada y asumida por la Comisión de Familiares de Caídos en Malvinas, con lo cual, sumado a la planificación y gestión de los viajes, su capacidad de decisión sobre los cuerpos enterrados fue casi total. En 2001, la Comisión puso en marcha una colecta para la construcción de dicho panteón bajo el lema De todos los argentinos, para los argentinos que nos dieron todo.

No obstante, entre 2003 y 2005, la construcción del monumento en Darwin ingresó como problema de Estado anclado fundamentalmente a su financiamiento y manutención. En 2003, el senador Mario Colazo (UCR) solicitó un subsidio destinado a la Comisión de Familiares para mostrar que el Congreso no era pasivo ante "hechos que quedarán incorporados a la memoria colectiva y a la historia nacional" (Honorable Cámara de Senadores, 2003). En febrero de 2004 partió un buque desde Buenos Aires (el BBC Japan) que transportó el material destinado a la obra, y fue despedido en un acto oficial destacado por un diputado como un acontecimiento que "lleva implícito el firme compromiso del gobierno nacional y del pueblo argentino en su conjunto de no cesar en el reclamo de soberanía sobre estas tierras" (Honorable Cámara de Diputados, 2004). En la imaginación de dichos representantes legislativos, el cementerio era parte de las piezas históricas del museo de la patria.

Corría el mes de marzo de 2005 cuando el presidente Néstor Kirchner (2003-2007, PJ) decidió auspiciar el viaje de miembros de la Comisión de Familiares para supervisar las obras del monumento. El decreto de auspicio se fundamentó en el proceso de reconciliación con los británicos que el acuerdo de 1999 significó. Luego de dicho viaje, los familiares informaron al gobierno que las obras estaban concluidas. No obstante, en 2006, el jefe de Gabinete de Ministros de la Nación, Alberto Fernández, remarcó que la declaración conjunta entre Argentina y Gran Bretaña no preveía una inauguración, por lo cual su concreción dependía de la buena voluntad del gobierno inglés (Jefatura de Gabinete de Ministros de la Nación, 2006). Sin embargo, los años siguientes marcarían una creciente distancia entre los gobiernos británico y argentino, en la cual la inauguración quedaría como prenda de disputa y tensión.

Con ese marco mediante, en 2008 el Ejecutivo declaró lugar histórico "al cementerio ubicado en Puerto Darwin, Isla Soledad, archipiélago de las Islas Malvinas (Datos: $51^{\circ} 48^{\prime}$ de latitud sur y $58^{\circ}$ 59' de longitud oeste), a ochenta y ocho (88) kilómetros de Puerto Argentino, en la provincia de Tierra del Fuego, Antártida e islas del Atlántico Sur" (Boletín Oficial de la República Argentina, 2008). Por primera vez, y más allá de ser un instrumento simbólico, un texto promulgado estableció la soberanía argentina sobre la necrópolis poniéndolo en el mismo rango de la tumba de guerra en las aguas que acogieron al ARA General Belgrano ${ }^{12}$. Paralelamente los diputados Jorge Coscia, Eduardo Fellner y Carlos Kunkel (PJ) presentaron un proyecto para que esa declaración se establezca por ley y extienda su denominación a cementerio de guerra. El texto indicó que la Comisión de Familiares de Caídos en Malvinas sería la encargada de "asegurar la custodia, conservación,

En 2002 la ley 25.546 declaró lugar histórico y tumba de guerra a la zona del hundimiento del buque argentino ARA General Belgrano, torpedeado por un submarino británico durante la guerra y donde murieron 323 personas. En el texto se señaló que los restos de los tripulantes no serían perturbados salvo que "la mayor parte de sus familiares reclame su recuperación" (Boletín Oficial de la República Argentina, 2002). A diferencia de los textos que tomaron a Darwin como problema, en este caso el reclamo de los cuerpos sí ingresó como posibilidad, pese a la ambigüedad de esa mayoría necesaria. 
refacción y restauración" del espacio dándole un rango estatal. En sus fundamentos, los legisladores afirmaron que

esta iniciativa, además de un acto de justicia, es también un acto de resguardo y proyección hacia los restos mortales de los que yacen sepultados, pues son conocidas las intenciones de algunos sectores británicos por borrar todo vestigio de la decisión argentina por recuperar las islas, y los restos de los héroes nacionales son la más contundente demostración de esa voluntad (Honorable Cámara de Diputados, 2008).

El resguardo de los restos fue la diferencia principal entre la tumba submarina del Belgrano y Darwin: si la ley posibilitaba que los cuerpos hundidos en el mar pudieran ser reclamados y, por ende, re inhumados, los del cementerio isleño fueron tapados por el halo de nacionalismo que demostraba el deseo argentino de recuperar Malvinas, y puestos al resguardo de una Comisión que históricamente negó la posibilidad de reconocimiento de los soldados enterrados como NN (Lorenz, 2012: 357). El monumento, pese a que la fecha de su inauguración aún era una incógnita, emergía como un espacio de puro simbolismo para sostener un conjunto de argumentos de larga data.

El 2 de abril de 2009, y desde Londres, la presidenta Cristina Fernández de Kirchner (2007-2015, PJ) saludó a los caídos desde el monumento a San Martín de esa ciudad y afirmó que su gobierno instaba a la discusión sobre la soberanía en Malvinas. A las claras, la reconciliación había terminado o al menos aquel paraguas menemista se cerró. Al mes siguiente, la Cámara de Senadores aprobó el proyecto que declaraba al cementerio y su monumento como lugar histórico, el cual se promulgó sin modificaciones bajo ley $\mathrm{N}^{\circ}$ 26.498/2009.

En ese contexto, las negociaciones por la inauguración del monumento no fueron fáciles, aunque lograron destrabarse y la aprobación del viaje, con carácter humanitario, se pactó para los primeros días de octubre de 2009. El 3 de ese mes, la presidenta despidió al contingente de familiares y funcionarios asegurándoles que "no solamente van a ver a sus muertos, sino a los muertos de todos" y aseguró que "un día un presidente argentino va a ir a rendir homenaje a sus muertos, en nombre de los derechos legítimos que tenemos sobre esas islas" (Lorenz, 2012: 358). Con sus palabras la primera mandataria volvió a plantear como una e indivisible las dos soberanías puestas en juego, es decir la de los deudos sobre los cuerpos y la del Estado sobre el territorio. Para Fernández de Kirchner, los muertos de Darwin simbolizaban un solo problema: los derechos de la nación.

El viaje desató una enorme cantidad de expresiones de beneplácito y satisfacción muy comunes en las legislaturas. En una de ellas, que entre otras llevó la firma de Carlos Kunkel (PJ-FPV), uno de los autores del proyecto que declaró lugar histórico a la necrópolis de Darwin, manifestó que el viaje cerró una lucha de 27 años que, entre otras cosas, mostró el impacto que tuvo en las familias y en la sociedad "que las tumbas de los héroes" no tuvieran nombre y que únicamente pueda leerse en ellas la inscripción "soldado argentino sólo conocido por Dios" (Honorable Cámara de Diputados, 2009).

Dicha potestad (la que daba a Dios la posibilidad de ser el único conocedor de la identidad de los muertos) pocas veces había sido puesta en duda en la práctica discursiva política. Desde 1982 hasta 2009, el gobierno de los cuerpos en Malvinas había enfocado sus acciones en viajes, encuentros y monumentos prácticamente sin problematizar la identificación fehaciente de los cadáveres sin nombre que fueron producto, como vimos, de la improvisación de quienes comandaron y ejecutaron la guerra. Se naturalizó que la soberanía de los deudos sobre sus muertos se ejercía facilitando el viaje, y no se incorporó el pedido de identificación que otros organismos pedían por fuera de la Comisión de Familiares (Pirich, 2015; Guerrero, 2021).

El trigésimo aniversario de la guerra, cuando a nivel diplomático el gobierno de Cristina Fernández acentuó su discurso sobre la soberanía de Malvinas (Weiner, 2013), fue el momento en donde la identificación de los restos cobró mayor relevancia. En un acto realizado en abril de 2012 la presidenta afirmó haber dirigido una "carta al titular de la Cruz Roja internacional para que interceda en identificar a los hombres argentinos e ingleses que no han podido ser identificados" porque "cada madre tiene derecho de llorar a sus hijos muertos" (Fernández de Kirchner, 2012). En un discurso con menos épica que en otras oportunidades señaló que la guerra no fue "decisión del pueblo" y que "porque hemos sido víctimas de muchas guerras, pedimos justicia". Sin modificar el derecho sobre las islas, la mandataria desactiva el puente entre la soberanía del territorio y la de los cuerpos. Ya no son nuestros muertos sino los muertos de cada madre, víctimas de una guerra que no quisieron. De este modo, y después de 30 años, las razones humanitarias y los derechos a la identidad de los soldados caídos en Malvinas se conectan en la voz de un mandatario argentino. En el homenaje realizado por la Cámara de Senadores, el legislador Pablo González (PJ-FPV) pidió recordar al soldado José Honorio Ortega, uno de los soldados sólo conocido por Dios y en su nombre a todos los anónimos que "yacen en las tumbas de Darwin" (Honorable Cámara de Senadores, 2012).

En ese contexto, el diputado Oscar Aguad (UCR), con gran poder de sincretismo dóxico, unificó un conjunto de aspectos que giraron durante años en torno a los enterrados en la necrópolis. Al pedir un informe sobre las medidas a adoptar en la identificación, marcó que

nos guían sentimientos humanitarios fundamentales ante una tragedia como fue la guerra, porque la muerte no tiene nacionalidad, y entender que buscar una solución conjunta a este pedido no significa dejar de lado la firmeza en el reclamo por la soberanía de las islas. 
La memoria es un ejercicio de construcción colectiva permanente y reconstruir la gesta de Malvinas, en toda la extensión de su significado, exige, nos exige, el necesario y obligatorio homenaje a quienes dieron todo por la patria. El derecho a la identidad es una asignatura pendiente de todos los argentinos con aquellos que fueron a Malvinas y dejaron su vida allí. Ellos fueron hijos, padres, hermanos y amigos, ellos son los herederos directos de nuestros soldados de la Independencia, ellos son nuestros héroes contemporáneos (Honorable Cámara de Diputados, 2012).

Las palabras de Aguad encerraron un enorme conjunto de lugares comunes de la posguerra como memoria, olvido, razones humanitarias, soberanía, gesta, patria, derecho a la identidad, héroes de la independencia que a su vez son contemporáneos; lo que nos muestra que la identificación de estos cuerpos generó un impacto en los modos en que los muertos en Malvinas fueron problematizados como asunto de Estado. En 2013, Cristina Fernández de Kirchner encabezó el acto aniversario en la ciudad de Puerto Madryn donde saludó especialmente a los familiares de los " $123 \mathrm{NN}$, soldado argentino sólo conocido por Dios que esperamos poder identificar prontamente”. En su alocución, la mandataria afirmó que su gobierno tomó contacto y tuvo la aprobación del 75\% (91 familias según sus palabras) de los deudos, exigencia de la Cruz Roja Internacional para iniciar las acciones de identificación. Las madres volvieron a ser un motor argumental, pues los caídos

merecen tener una placa con su nombre y apellido, que cada madre pueda hincarse en esa tumba, rezarle a su hijo y ponerle una flor. No estamos pidiendo nada más que eso, un elemental ejercicio del más elemental de los derechos humanos que es velar y honrar a nuestros muertos (Fernández de Kirchner, 2013).

En 2014, el gobierno británico aceptó colaborar con Argentina aunque las tensiones entre ambos gobiernos entorpecieron la marcha. Ese mismo año, el senador Luis Juez (Frente Amplio Progresista) presentó un proyecto de ley con el fin de crear un Banco Genético de Datos para alojar muestras que permitan la identificación, gestionado por la Secretaría de Derechos Humanos y como órgano de consulta al Equipo Argentino de Antropología Forense. Para el legislador, este sería el homenaje póstumo más importante puesto que la soledad de Dios en su reconocimiento no es tal ya que "todos los conocemos, sabemos de sus familias, de su heroica participación en la guerra y hasta cómo murieron defendiendo la patria. Solo resta identificarlos" (Honorable Cámara de Senadores, 2014). El texto inscribió el pedido en el marco de los derechos individuales internacionales, pero sin obviar que "su patriotismo ha trascendido a sus familias y hoy, todos los argentinos, nos merecemos saber dónde descansan nuestros héroes, para saber quiénes son y desde qué posición siguen custodiando nuestro suelo".

Al año siguiente, en su último discurso encabezando un aniversario de la guerra, Fernández de Kirchner ubicó a los mártires no identificados en Darwin entre los "los pibes que fueron a morir por su bandera" (Fernández de Kirchner, 2015a). Un día después la mandataria firmó el decreto de desclasificación de los archivos militares ligados al conflicto y resguardados bajo secreto de Estado desde la dictadura. En su alocución, la presidenta retomó las referencias sobre el martirologio de los muertos para llamarlos

verdaderos mártires en la lucha contra el colonialismo y en la lucha por la independencia definitiva de nuestro país, por lo menos la independencia territorial, que todavía falta, nos falta un cachito, nos falta un cacho de independencia territorial, pese al 9 de Julio ${ }^{13}$. No va a haber un 9 de Julio completo hasta que no podamos recuperar nuestras Islas Malvinas (Fernández de Kirchner, 2015b).

En sus últimas palabras públicas sobre el tema, Cristina Fernández volvió a situar a la soberanía de los cuerpos como un problema de soberanía territorial.

\section{Conclusiones}

A fines de noviembre de 2016, cercano al primer año de mandato de Mauricio Macri (Propuesta Republicana, PRO), se hizo público el acuerdo firmado por los gobiernos de Argentina y Gran Bretaña por intermediación de la Cruz Roja Internacional denominado Plan Proyecto Humanitario (PPH). Las tareas de re inhumación llevaron poco menos de un año y a finales de 2017 los organismos involucrados junto al Estado argentino iniciaron la puesta en contacto con los familiares para organizar la colocación de las placas grabadas con algunos de los nombres restituidos. Como dijimos en la introducción, en marzo de 2018 se llevó a cabo el viaje de familiares con las nuevas lápidas.

Este hecho quebró un modo de gobierno de los cuerpos muertos que tuvo, como vimos, su piedra fundacional pocos meses después de alto al fuego en 1982. En estas líneas intentamos mostrar cómo los discursos políticos (en nuestro trabajo, los textos políticos) lejos están de ser solo un problema de sentido, y deben ser vistos como una palanca para entender los modos en que somos gobernados y las formas en que lo real y lo posible puede ser objetos de pensamiento. Vimos cómo la dictadura militar conectó dos aspectos (los muertos

$13 \quad$ El 9 de julio se celebra en Argentina el día de la Independencia. 
en la guerra y la soberanía sobre el territorio) como un problema único e indisoluble, que más allá de ser una cuestión estratégica de salida del poder se imbricó cómodamente en el pensamiento político sobre la cuestión Malvinas. Esta problematización primigenia se sintetizó en una máxima: los cuerpos enterrados están en su patria y la patria los traerá a continente cuando las Malvinas sean recuperadas al territorio nacional.

El juego entre el derecho y la soberanía abrió dos vertientes que por momentos se deslindaron y en otros aparecieron juntas: la soberanía y el derecho de los familiares sobre los cuerpos (cuyo sostén fue el carácter humanitario de los viajes de familiares a las tumbas), y las de la nación sobre el territorio donde éstos yacen, unidad soñada por los militares en 1983 y cuyo quiebre tardó casi 30 años en concretarse. Dicho quiebre se manifestó en el ingreso y estabilización de que la soberanía de los deudos sobre sus seres queridos excedía la visita a Darwin y el tiempo de recuperación de Malvinas al pabellón nacional, conectando lo humanitario con la identidad de los soldados desconocidos y devolviendo la potestad del futuro de los restos reinhumados a las familias. Al estar ligado al proceso de heroización constante de los muertos de la guerra, el imaginario patriótico concentró gran parte de los argumentos sobre los cuerpos enterrados, inmovilizándolos durante más de tres décadas como otra pieza más del museo de la patria.

A nuestro modo de ver, el enfoque WPR, y en particular la concentración sobre los problemas en cuestión que se representan, nos ayuda a seguir un hilo que tiene una larga duración, que atraviesa todas las posiciones ideológicas y que separó por mucho tiempo a hombres y mujeres, hijos, padres, parejas, de la posibilidad de rendir tributo y cumplir una parte de esa actividad tan humana llamada duelo. Esta inmovilización y heroización impactó incluso al nivel de impedir por más de 35 años el reconocimiento de aquellos restos que permanecían como NN y por ende de posibilitar que sus deudos puedan llorar la muerte sobre una tumba.

La paradoja de esta separación es que se mostró como el mejor camino posible y pensable respecto a los restos enterrados en las islas y la posibilidad de que sus deudos puedan tener contacto con ellos. La potencialidad de este enfoque es que, justamente, antes de echar culpas sobre posiciones políticas, muestra la solidez con que una configuración primigenia, una acumulación originaria de sentido dada en la temprana posguerra, puede generar un impacto tal que, aun hoy, es difícil de interpretar.

\section{Bibliografía}

Bacchi, C. \& S. Goodwin (2016): Poststructural Policy Analysis. A Guide to Practice, New York, Palgrave Macmillan.

Bacchi, C. (2009): Analysing policy. What's the problem represented to be?, Melbourne, Pearson Australia.

Bacchi, C. (2015) "The Turn to Problematization: Political Implications of Contrasting Interpretive and Poststructural Adaptations", Open Journal of Political Science, 5 (enero), pp. 1-12, DOI http://dx.doi.org/10.4236/ojps.2015.51001

Boletín Oficial de la República Argentina (1991): Decreto 364/91. BORA No 27.092 del 12 de marzo de 1991. Disponible en web https://www.boletinoficial.gob.ar [Consulta: 03 de enero de 2019]

Boletín Oficial de la República Argentina (2002): Ley 25.546/2002. BORA No 29.812 del 9 de enero de 2002. Disponible en web https://www.boletinoficial.gob.ar [Consulta: 03 de enero de 2019]

Boletín Oficial de la República Argentina (2008): Decreto 2131/2008. BORA N 31.557 del 22 de diciembre de 2008. Disponible en web https://www.boletinoficial.gob.ar [Consulta: 03 de enero de 2019]

Bologna, B. (1992): El conflicto de las islas Malvinas, Rosario, Ediciones Facultad.

Burchell, G., C. Gordon y P. Miller (1991): The Foucault effect. Studies in governmentaliy, Chicago, The University of Chicago Press.

Castel, R. (1997): La metamorfosis de la cuestión social, Buenos Aires, Editorial Paidós.

Deacon, R (2002): “Theory as practice: Foucault’s concept of problematization”, Telos, 118 (invierno), pp. 127-142.

Dean, M. (2010): Governmentality. Power and Rule in Modern Society, London, Sage Publications.

Fernández de Kirchner, C. (2012): "No fue una decisión del pueblo la del 2 de abril". Diario Uno. 3 de abril de 2012. Disponible en web https://www.diariouno.com.ar/pais/cristina-fernandez-no-fue-una-decision-del-pueblo-la-del-2-abril20120402-n124235.html. [Consulta: 05 de enero de 2019]

Fernández de Kirchner, C. (2013): "Palabras de CFK en el $31^{\circ}$ aniversario del inicio de la Guerra de Malvinas, en Puerto Madryn". 2 de Abril de 2013. Disponible en web http://www.cfkargentina.com/category/cfk/discursos/. [Consulta: 05 de enero de 2019]

Fernández de Kirchner, C. (2015a): "Cristina, acto central del día del Veterano y de los Caídos en la guerra de Malvinas, en Ushuaia". 2 de Abril de 2015. Disponible en web http://www.cfkargentina.com/category/cfk/discursos/. [Consulta: 05 de enero de 2019]

Fernández de Kirchner, C. (2015b). "Firma del Decreto № 503 que desclasifica toda la información que obra y que hay sobre Islas Malvinas". 3 de abril de 2015. Disponible en web http://www.cfkargentina.com/category/cfk/discursos/. [Consulta: 05 de enero de 2019]

Foucault, M. (1982): “El polvo y la nube”, La imposible prisión: debate con Michel Foucault, Barcelona, Anagrama, pp. 37-54.

Foucault, M. (1999): "Polémica, política y problematizaciones. Entrevista con P. Rabinow”, Estética, ética y hermenéutica. Obras Esenciales. Volumen III, Barcelona, Paidós, pp. 353-362.

Foucault, M. (2012): Historia de la sexualidad 2: el uso de los placeres, Madrid, Biblioteca Nueva.

Fuerza Aérea Argentina (1983): Traslado de restos del personal caído e inhumado en Malvinas. Fuerza Aérea Argentina. Estudio de Estado Mayor, FAA, Departamento de Estudios Históricos de la Fuerza Aérea Argentina, Fondo Colección Malvinas, Caja 12 , Carpeta 8.

Gordon, C. (2015): “Racionalidad gubernamental: una introducción”, Nuevo Itinerario, 10 (1), pp. 1-58. 
Guber, R. (2001): ¿Por qué Malvinas? De la causa nacional a la guerra absurda, Buenos Aires, Fondo de Cultura Económica.

Guber, R. (2004): De "chicos" a "veteranos": memorias argentinas de la guerra de Malvinas, Antropofagia-IDES, Buenos Aires.

Guerrero, L (2021): La otra guerra. Una historia del cementerio argentino en las islas Malvinas, Anagrama, Barcelona.

Honorable Cámara de Diputados de la Nación (1984): Diario de sesiones, $20^{\circ}$ reunión, 29 y 30 de marzo de 1984, HCD, Buenos Aires, Hemeroteca Revistas, Biblioteca del Congreso de la Nación.

Honorable Cámara de Diputados de la Nación (1991a): Proyecto de declaración $N^{\circ}$ 5749-D-90. Trámite Parlamentario $N^{\circ} 229$, 21 de marzo de 1991. Autor: Saturnino Aranda (PJ), HCD, Buenos Aires, Hemeroteca Revistas, Biblioteca del Congreso de la Nación.

Honorable Cámara de Diputados de la Nación (1991b): Proyecto de declaración $N^{\circ}$ 5668-D-91. Trámite Parlamentario $N^{\circ} 226$, 14 de marzo de 1991, HCD, Buenos Aires, Hemeroteca Revistas, Biblioteca del Congreso de la Nación.

Honorable Cámara de Diputados de la Nación (1996): Proyecto de declaración $N^{\circ} 3293-D-96$. Trámite Parlamentario $N^{\circ} 79,24$ de junio de 1996, HCD, Buenos Aires, Hemeroteca Revistas, Biblioteca del Congreso de la Nación.

Honorable Cámara de Diputados de la Nación (1997a): Proyecto de ley $N^{\circ}$ 3132-D-97. Trámite Parlamentario $N^{\circ}$ 67, 6 de junio de 1997, HCD, Buenos Aires, Hemeroteca Revistas, Biblioteca del Congreso de la Nación.

Honorable Cámara de Diputados de la Nación (1997b): Proyecto de declaración $N^{\circ}$ 666-D-97. Trámite Parlamentario $N^{\circ} 10,14$ de marzo de 1997, HCD, Hemeroteca Revistas, Biblioteca del Congreso de la Nación.

Honorable Cámara de Diputados de la Nación (1997c): Proyecto de declaración No 929-D-97. Trámite Parlamentario $N^{\circ} 14,14$ de marzo de 1997, HCD, Buenos Aires, Hemeroteca Revistas, Biblioteca del Congreso de la Nación.

Honorable Cámara de Diputados de la Nación (2001a): Proyecto de ley $N^{\circ} 1311-D-2001$. Trámite Parlamentario $N^{\circ} 21,28$ de marzo de 2001, HCD, Disponible en web http://www.diputados.gov.ar [Consulta: 03 de enero de 2019]

Honorable Cámara de Diputados de la Nación (2001b): Diario de sesiones, $10^{\circ}$ reunión, 9 de mayo de 2001, HCD, Disponible en web http://www.diputados.gov.ar. [Consulta: 03 de enero de 2019]

Honorable Cámara de Diputados de la Nación (2004): Proyecto de declaración $N^{\circ} 124-D-2004$. Orden del día $N^{\circ} 87,20$ de abril de 2004, HCD, Disponible en http://www.diputados.gov.ar. [Consulta: 03 de enero de 2019]

Honorable Cámara de Diputados de la Nación (2008): Proyecto de ley $N^{\circ} 4.414-D-2008$. Orden del día $N^{\circ} 1176,12$ de noviembre de 2008, HCD, Disponible en web http://www.diputados.gov.ar. [Consulta: 03 de enero de 2019]

Honorable Cámara de Diputados de la Nación (2009): Proyecto de resolución $N^{\circ}$ 4921-D-2009. Trámite Parlamentario $N^{\circ} 134$, 8 de octubre de 2009, HCD, Disponible en web http://www.diputados.gov.ar. [Consulta: 03 de enero de 2019]

Honorable Cámara de Diputados de la Nación (2012): Proyecto de resolución $N^{\circ}$ 669-D-2012. Trámite Parlamentario $N^{\circ} 5,13$ de marzo de 2012, HCD, Disponible en web http://www.diputados.gov.ar. [Consulta: 03 de enero de 2019]

Honorable Cámara de Senadores de la Nación (1997): Proyecto de resolución N ${ }^{\circ}$ S-2842-96. Diario de Asuntos Entrados $N^{\circ} 194$, 26 de febrero de 1997, HCS, Buenos Aires, Hemeroteca Revistas, Biblioteca del Congreso de la Nación.

Honorable Cámara de Senadores de la Nación (2003): Proyecto de resolución $N^{\circ}$ S-1837-2003. Diario de Asuntos Entrados $N^{\circ}$ 112, 17 de septiembre de 2003, HCS, Disponible en web http://www.senado.gov.ar. [Consulta: 06 de enero de 2019]

Honorable Cámara de Senadores de la Nación (2012): Diario de sesiones, $2^{\circ}$ reunión, 14 de marzo de 2012, HCS, Disponible en web http://www.senado.gov.ar. [Consulta: 06 de enero de 2019]

Honorable Cámara de Senadores de la Nación (2014): Proyecto de ley S-1743-2014. Diario de Asuntos Entrados $N^{\circ} 85,2$ de julio de 2014, HCS, Disponible en web http://www.senado.gov.ar. [Consulta: 06 de enero de 2019]

Jefatura de Gabinete de Ministros de la Nación (2006): Informe $N^{\circ} 67$ del Jefe de Gabinete de Ministros ante el Honorable Congreso de la Nación. Julio de 2006, HCS, Disponible en web http://www.diputados.gov.ar/secparl/dgral_info_parlamentaria/dip/ informes. [Consulta: 03 de enero de 2019]

Lorenz, F. (2012): Las guerras por Malvinas, Buenos Aires, Edhasa.

Lorenz, F. (2017): La llamada: historia de un rumor de la posguerra de Malvinas, San Miguel de Tucumán, EDUNT.

Ministerio de Defensa (2014): Actas de la Dictadura: documentos de la Junta Militar encontrados en el Edificio Cóndor. Tomo $V$, Buenos Aires, Ministerio de Defensa.

Ministerio de Relaciones Exteriores (1983): Informe Cruz Roja Internacional. Prisioneros de guerra. MRE. Departamento de Estudios Históricos de la Fuerza Aérea. Fondo Colección Malvinas. Caja 30. Carpeta 4.

Ministerio de Relaciones Exteriores (1999): Declaración conjunta de los gobiernos del Reino Unido de Gran Bretaña y la Argentina. 13 y 14 de julio de 1999, Ministerio de Relaciones Exteriores, Comercio Internacional y Culto, Disponible en web https://www.mrecic.gov.ar/userfiles/documentos-malvinas/1999_declaracion_conjunta.pdf. [Consulta: 06 de enero de 2019]

Palermo, V. (2014): Sal en las heridas. Las Malvinas en la cultura argentina contemporánea, Buenos Aires, Pengüin Random House.

Panizo, L (2011): Donde están nuestros muertos. Experiencias rituales de familiares de desaparecidos de la última dictadura militar en la Argentina y de caídos en la Guerra de Malvinas, Tesis doctoral inédita, Universidad de Buenos Aires, Buenos Aires.

Panizo, L. (2016): "La guerra sentida: símbolos rituales entre familiares y ex combatientes de la Guerra de Malvinas”, Sociedad y Religión, 46 (XXVI), pp. 84-113.

Pirich, G. (2015): Hojas de ruta. De la guerra en las Islas a la guerra en el continente, Buenos Aires, Dunken.

Weiner, S. (2013): "Política del gobierno argentino en torno de la 'cuestión' Malvinas y su incidencia en la región”, Espiral. Estudios sobre Estado y Sociedad, 57, pp. 129-151. 
